\title{
Papillary thyroid microcarcinoma (Black Ink)
}

Case Report

\author{
Ersilio Trapanese $^{1}$, Carmine De Bartolomeis ${ }^{2}$, Basilio Angrisani ${ }^{3}$ and Giulio Tarro ${ }^{4,5}$ \\ ${ }^{1}$ Interventional Ultrasound of Breast Oncology Screening, ASL Salerno, Salerno, Italy \\ ${ }^{2}$ Endocrine Surgery and General Surgery Specialist, University Pisa, Pisa, Italy \\ ${ }^{3}$ Anatomical Pathology Specialist, University Hospital of Campania "L. Vanvitelli", Naples, Italy \\ ${ }^{4}$ President Foundation T. \& L. de Beaumont Bonelli for Cancer Research, Naples, Italy \\ ${ }^{5}$ Chairman of the VirusSphere World Academy of Biomedical Technologies (WABT) UNESCO, Paris, France \\ Correspondence to: Giulio Tarro, email: givliotarro@gmail.com \\ Keywords: Ultrasonography; ADF; FNAC; thyroid microcarcinoma; Black Ink
}

Received: March 07, $2018 \quad$ Accepted: May 25, $2018 \quad$ Published: June 26, 2018

Copyright: Trapanese et al. This is an open-access article distributed under the terms of the Creative Commons Attribution License 3.0 (CC BY 3.0), which permits unrestricted use, distribution, and reproduction in any medium, provided the original author and source are credited.

\section{ABSTRACT}

We report a case of a 58-year-old Caucasian woman affected by papillary thyroid microcarcinoma (PTMC) of the left-lobe of the gland with very small size $(\varnothing 0.3$ $\mathrm{cm})$. The characteristics with the Diagnostic Imaging using Ultrasonography, ADF (Advanced Dynamic Flow), and fine-needle-aspiration cytology (FNAC) are discussed, comprising a very small micro-focus of radial shape, with markedly hypoechoic echostructure, irregular margins, supplemented by peripheral vessel formation. It acquires an image which appears similar to a brisk visualization of a dark ink stain in the normal thyroid weave. We call such a pattern "Black Ink" with ultrasonographic image and believe consistent with the infiltrating variant of papillary thyroid microcarcinoma if associated with malignant cytology after FNA.

\section{INTRODUCTION}

According to WHO Papillary Microcarcinoma is any thyroid papillary carcinoma with a diameter of $1 \mathrm{~cm}$ or less [1]. These tumors are occasionally diagnosed as an incidental finding after thyroidectomy for other pathology or autopsy; some of these very small cancers are completely encapsulated and tend to behave indolently while some others clearly infiltrate the thyroid parenchyma. Malignant behavior has been proven by several authors $[2,3,4]$.

Clinical-pathological features and prognosis of this neoplasm, have been discussed in a previous study [5].

The most affected topographic anatomical area is the middle third of the right or left thyroid lobe. The tumor has mainly a woman distribution, with the age range between 27 - 75 years $[6,7]$. The cause of papillary carcinoma is unknown, there are risk factors for the development of thyroid cancer (ionizing radiation, iodine deficiency, autoimmunity, familiarity) $[8,9]$.
Ultrasonography represents the diagnostic technique for more sensitive images for an early diagnosis of thyroid lesion $[10,11,12,13]$.

The ADF (Advanced Dynamic Flow) allows to underline the vessel flow of the newly formed tortuous vessels [14].

The FNAC (Fine Needle Aspiration Cytology) has allowed the diagnosis with a $92-95 \%$ diagnostic accuracy (positive predictive value based mainly on the nuclear features of the cancer cells) [15].

We present a case of a infiltrating papillary thyroid microcarcinoma, size $0.3 \mathrm{~cm}$, identified on the ultrasound examination and $\mathrm{ADF}$ in the left of the thyroid lobe.

\section{CASE REPORT}

A 58-year-old Caucasian woman with no personal history of thyroid disease presented herself to perform a thyroid ultrasound examination.

Routine laboratory tests results were normal. BMI result was $33 \mathrm{~kg} / \mathrm{m} 2$. 
A sister was previously diagnosed of papillary thyroid carcinoma.

Bidimensional ultrasonography (DUS 2) using high frequency probes (13 - $15 \mathrm{MHz}$ ) (Toshiba Aplio 500) highlighted a highly suspicious micro-focus of the left lobe, of radial shape with markedly hypoechoic echostructure, irregular margins, size $0.3 \mathrm{~cm}$ (classified TI-RADS 5, very high risk lesion ATA guidelines).

(Figure 1-5).

ADF test showed a clear flow through newly formed tortuous vessels at the periphery of the specific microfocus (Figure 6, 7).

FNAC procedure was proposed to the patient and, after informed consent had been obtained, it was performed under ultrasound guidance (Figure 8).

Cytologic examination of the slides (Papanicolaou stain) allowed recognition of malignancy with cytologic pattern very suspicious for papillary tumor (TIR5 cathegory according to Italian Consensus, cathegory VI according to The Bethesda System for Reporting Thyroid Cytopathology (Figure 9, 10).

The patient became candidate for thyroidectomy and subsequently underwent a Total Extracapsular Thiroidectomy procedure (TT). Some enlarged lymph nodes (ENL) were evaluated ultrasonography previous to surgical exploration, and found and removed close to the left inferior thyroid pole at the time of thyroidectomy.

Histological examination of the lesion showed a proliferation of well differentiated epithelial cells forming an purely papillary structure surrounded by blood vessels, with irregular borders, overtly infiltranting thyroid parenchyma.

The neoplasm showed no relationship to thyroid capsule and no vascular or lymphatic invasion. All the lymph nodes retrieved were devoid of metastatic cells (final TNM $8^{\text {th }}$ eds. staging pT1, pN0) (Figure 11).

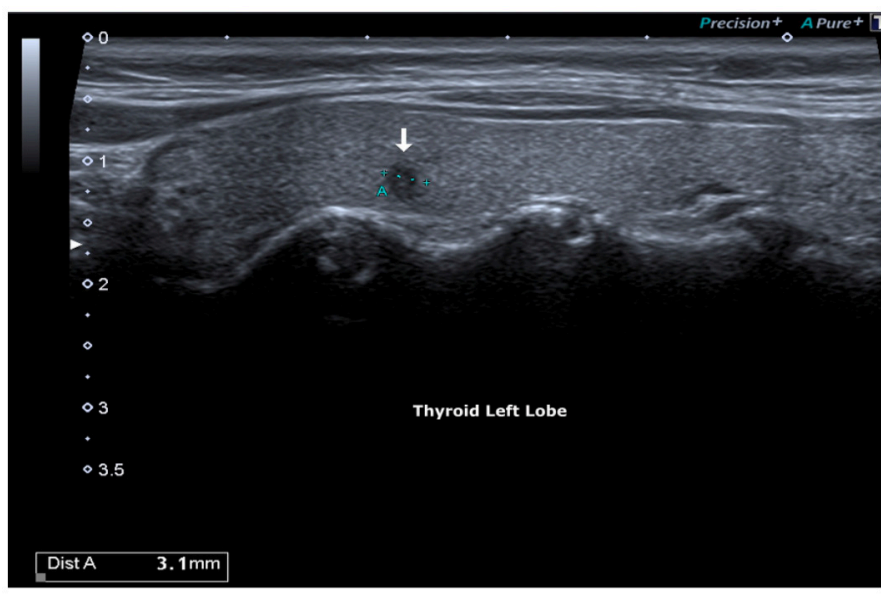

Figure 1: Hypoecogenic micro-focus, irregular margins.

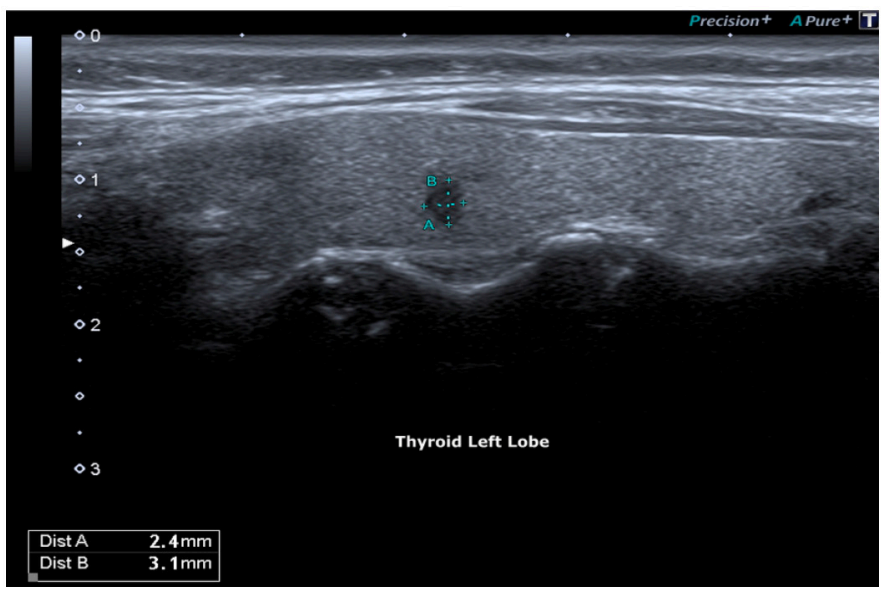

Figure 2: Micro-focus, irregular margins: 3 mm. 


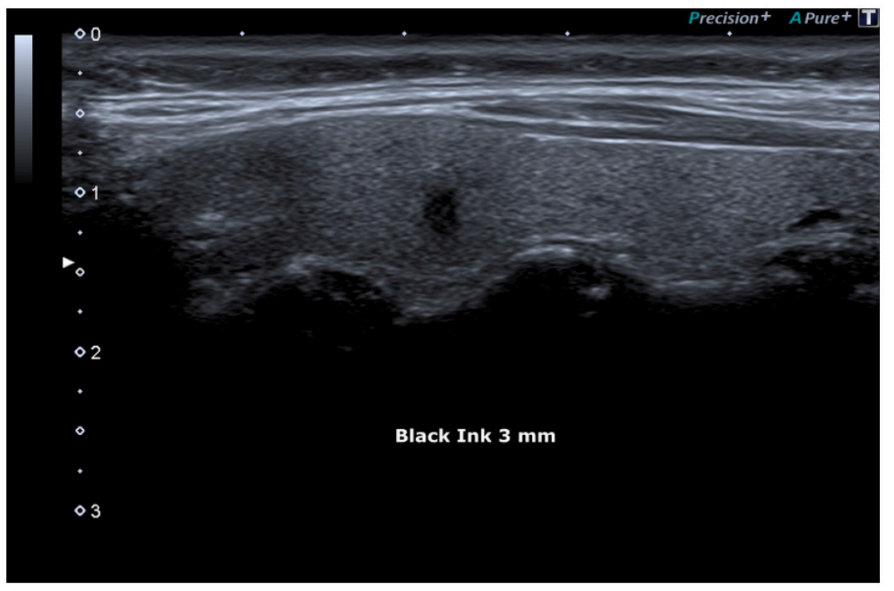

Figure 3: Black Ink.

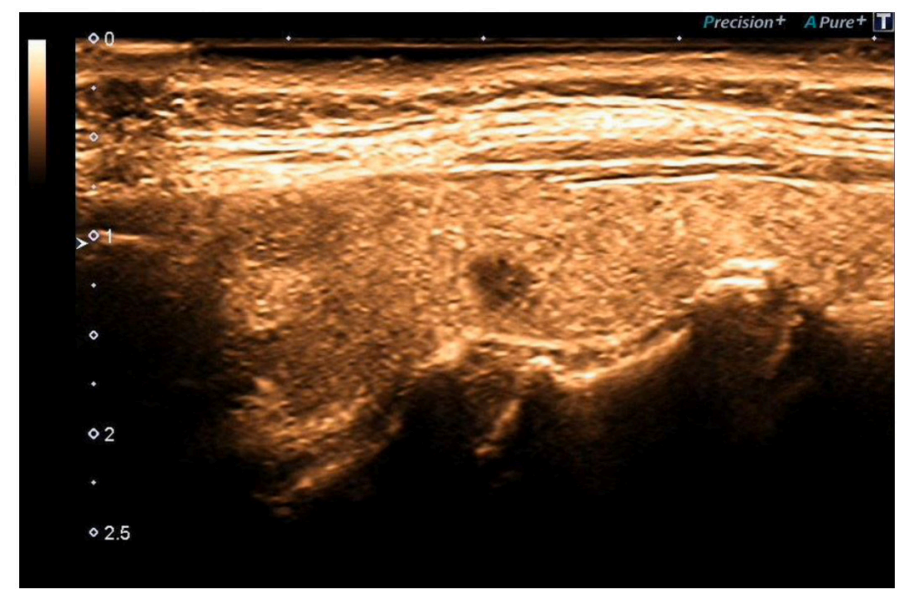

Figure 4: Black Ink.

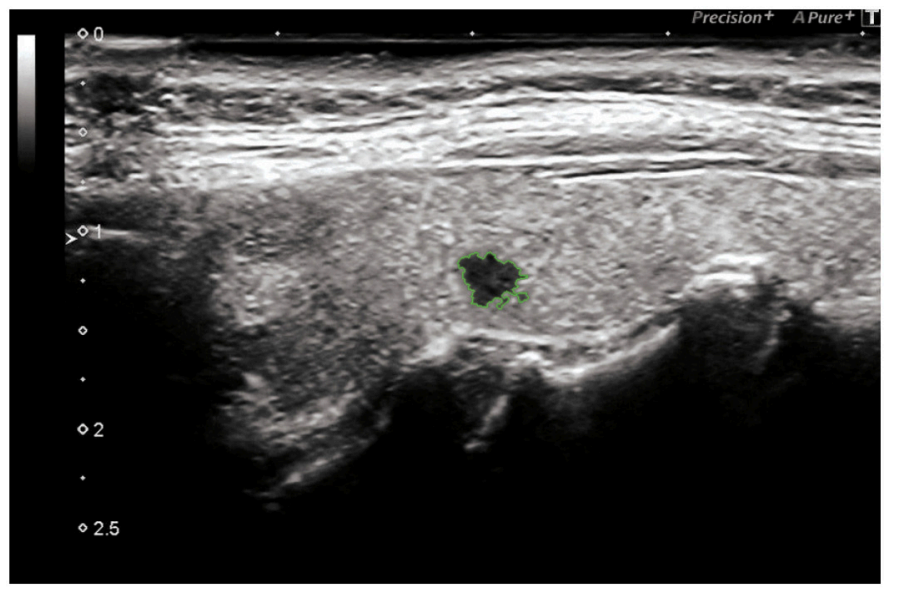

Figure 5: Black Ink, irregular margins: 3 mm. 


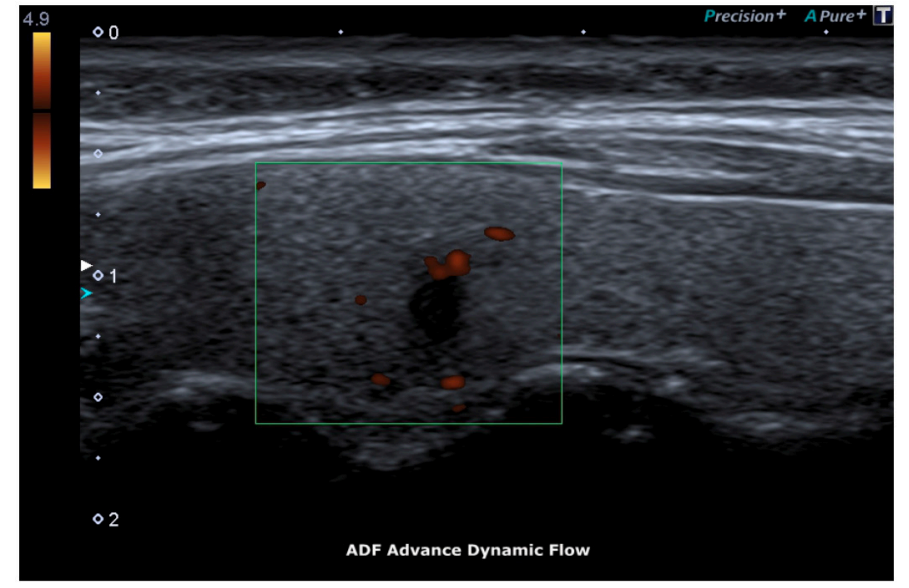

Figure 6: ADF, Advance Dynamic Flow.

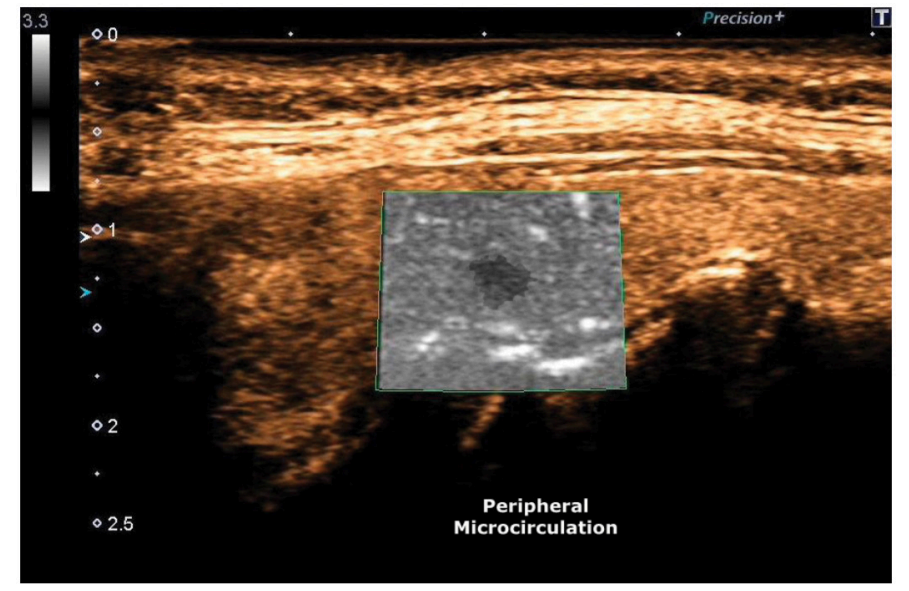

Figure 7: ADF, Peripheral Microcirculation.

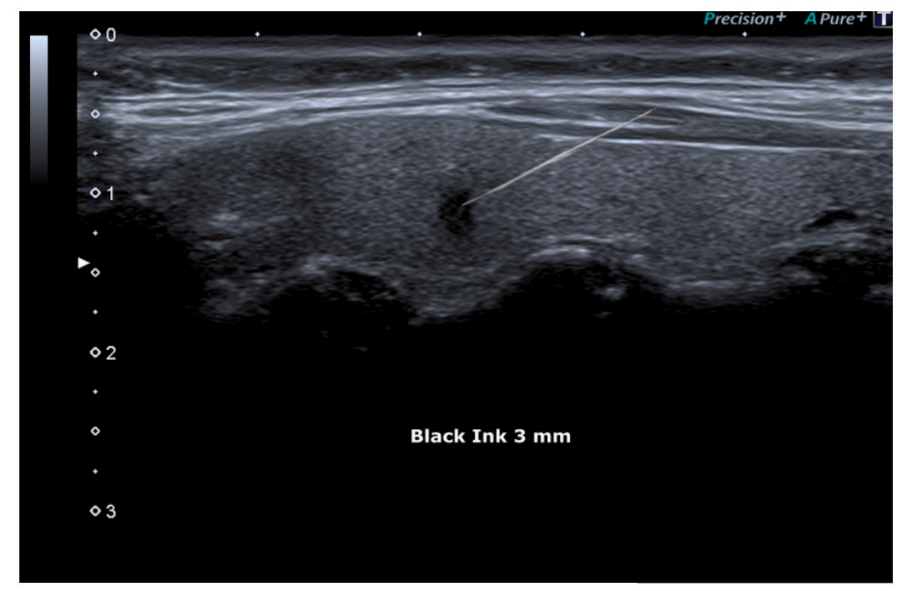

Figure 8: FNAC (Fine Needle Aspiration Cytology) Showed under guide. 


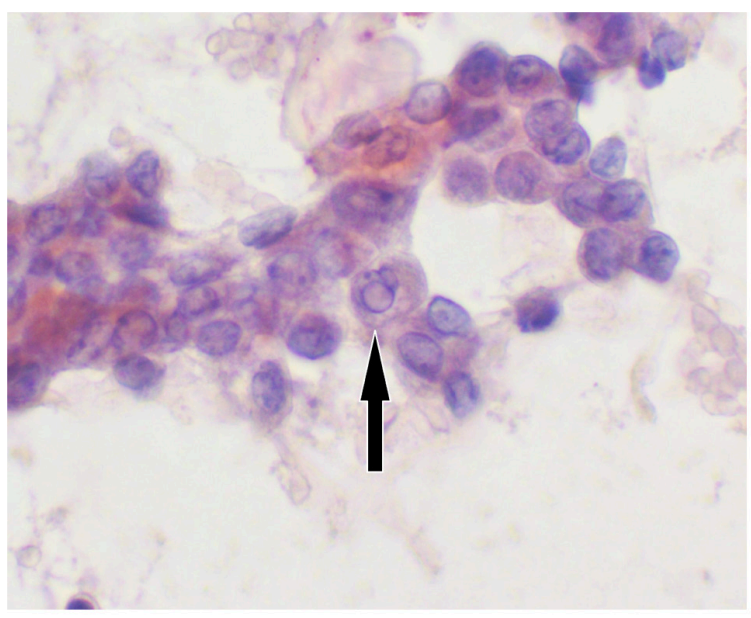

Figure 9: Zoom Cytology image. This illustrative cell group shows most important features of papillary carcinoma:nuclear grooves and pseudoinclusion.

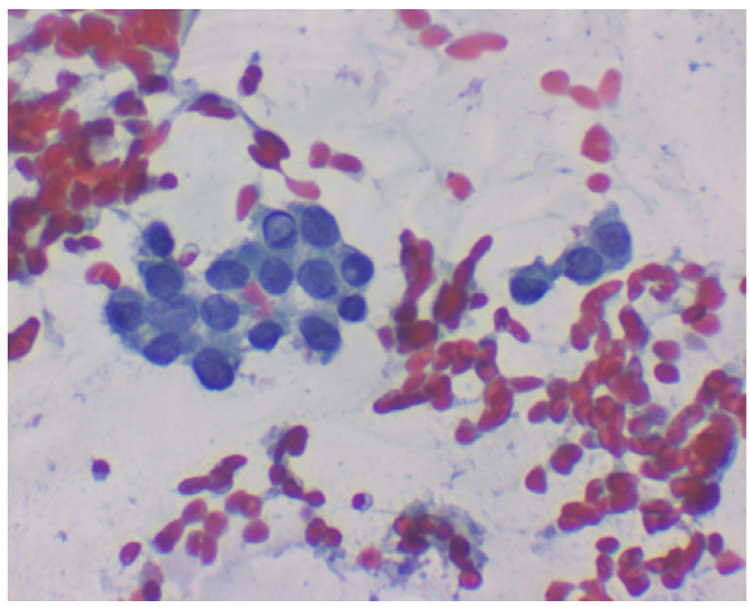

Figure 10: $(600 x)$ It shows clusters of cohesive epithelial cells with enlarged nuclei, incremented nuclear/cytoplasmicratio, nuclear crowding and presence of prominent nuclear grooves and pseudoinclusions.

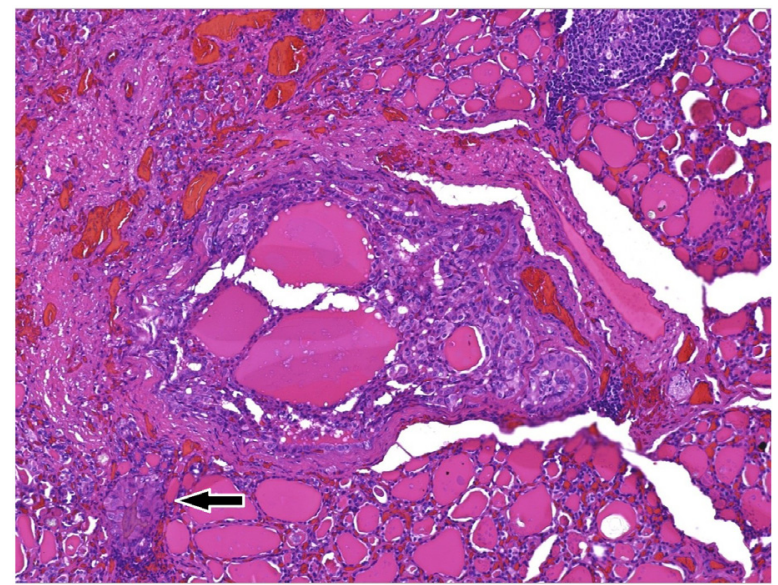

Figure 11: (100x) Whole section of the PTMC, classic variant, $\varnothing 0.3 \mathrm{~cm}$, devoid of a capsule structure, being made offollicoles and well formed papillae with fibrovascular core, irregular contour, surrounded by newly formed microvessels. White arrow highliths a papillary group of neoplastic cells penetrating normal thyroid follicoles at the periphery of the main focus, which indicates that the tumor already shows tendency to spread in the surrounding (invasion). 
Patient underwent hormonal and tumor markers evaluation plus ultrasonographic evaluation of the neck after 3 months. Post operative remnants therapy with Radioiodine I-131 (RAI), was not administered inasmuch the tumor was very little, contained in the thyroid and lacked vascular invasion.

\section{DISCUSSION}

Zhao [16] and Ghossein [17] argue that the difference of the papillary microcarcinoma is only for the size in comparison with other thyroid cancers and not for morphological, clinical and prognostic characteristics.

They report several cases of microcarcinoma followed by recurrence and aggressive behaviour with multiple metastases.

Kasai and Sakamoto [18] claim that the sizes of PTMC are markers of limph node metastasis and vascular invasion.

The micro-focus identified was localized at the middle third of the left lobe, presenting a radial shape, markedly hypoechoic echostructure, irregular margins, size $0.3 \mathrm{~cm}$, characteristics with a high predictive for malignancy value $(\mathrm{p}<0.001)$ [19]

The ADF allowed detection of microvascularization at the periphery of the micro-focus with accuracy.

Despite the small size of the lesion, the diagnostic image was strongly suspicious for malignancy and the FNAC procedure determined accurate detection of malignancy. Based on nuclear crowding and presence of prominent nucleargroves and pseudoinclusions FNAC was classified TIR5 according to the Italian consensus [20] and Category VI according to the Bethesda Classification [21].

Age and gender are considered prognostic factors for the recurrence and survival of PTMC patients [22, $23,24]$.

In papillary thyroid microcarcinoma (PTMC), a higher recurrence rate was noted in patients with a familiar history of PTMC, this remained predictive and indicates an increase in biological aggressiveness [25].

According to Hay [26] two are the important parameters to keep in mind in the possible onset of a reccurence: multifocality (number of focus) and the type of surgical treatment ( total thyroidectomy versus lobectomy).

Nevertheless, some authors suggest that there exist a subset of PTMCs that can be aggressive, requiring therapeutic management similar to larger tumors ( PTCs) $[27,28]$.

Familiarity, age and gender, for patients with these characteristics of high risk of long-term recurrence, total extracapsular thyroidectomy (TT), following the technique described by Lahey [29] and dissection of some enlarged lymph nodes (ELN), close to the left inferior thyroid pole, was considered to avoid reoperation (Hwangbo et al., 2017) [30]. (Supplementary Figures 1, 2).
Yokozoa [31] and Ahuia [32] have respectively documented that $15,9 \%$ of cancers less than 1 centimetre show an extra thyroid invasiveness and that occult metastasis of thyroid cancer to the limph nodes is up $20 \%$ of cases.

Cut surfaces showed a whitish equatorial nodule of $0.3 \times 0.2 \times 0.2 \mathrm{~cm}$ in the left lobe.

On histological examination the lesion was classified as papillary thyroid microcarcinoma (PTMC, classic variant), the neoplasm beeing made of well formed papillae intermingled focally with normal thyroid parenchima. Lymph node showed no involvement by tumor cells, and pathological stage was pT1a, pN0 according to TNM 8th edn $[33,34,35]$.

The tumor characteristics of the "Black Ink", highlighted in this case report, provides a reliable prognostic classification, in order to define an effective therapeutic plan.

Despite the small size of this micro-focus, dimension $0.3 \mathrm{~cm}$, this lesion is a variant of the papillary thyroid cancer with a potential aggressive behavior [36, 37, 38].

Being by nature, an infiltrating type, it is commonly classified in the dimensional group of small papillary tumors [39].

For these reasons, this case report has implemented an accurate analysis of the histological characteristics and of the long-term prognosis, underlining the differential diagnosis between the differentiated papillary microcarcinoma and the microcarcinoma infiltrating type. Mixing these different pathological entities within a common definition of "Papillary Thyroid Microcarcinoma (PTMC)" creates confusion in the communication process, and potentially compromises the management of a wellmeasured therapy in individual cases.

In recent years, several clinical and histologic risk factors for aggressiveness have been identified in PTMCs, such as size $\leq 0.5 \mathrm{~cm}$, multifocality, tumor extension beyond the parenchyma, limph node involvement [40].

Hawk [41] argues that size appears to be an important determinant of biological behavior of papillary carcinomas of the thyroid.

The optimal values of the size still remain controversial.

Lim et al., (2009) [42] indicated it would be $0.7 \mathrm{~cm}$, Zhang et al., (2012) [43] indicated it would be $0.6 \mathrm{~cm}$, and Chang et al. (2015) [44] indicated it would be $0.5 \mathrm{~cm}$.

It is very important that the size must be cautiously interpreted in the current increasing subgroup of PTMCs to verify which diameter would be more representative of the malignancy risk of nodules.

Wang et al. claim that the size of PTMC in ultrasound images are helpful to predict the aggressiveness of the tumors, it may become an easy predictor for PTMC prognosis and assist us to choose treatment (Wang et al., 2015) [45]. 


\section{CONCLUSIONS}

Thyroid cancer is among the most common cancers in women. We described a case of a 58-year-old woman with a $\varnothing 0.3 \mathrm{~cm}$ "Black Ink" image, which was subjected to FNAC and cytology examination and treated with total thyroidectomy with subsequent histology report of papillary thyroid microcarcinoma (invasive type). Ultrasonography together with FNAC have proven to be the most sensitive diagnostic imaging techniques for the early diagnosis of this thyroid neoplasm.

We are convinced that, despite the very small size of this micro-lesion, Black Ink echopattern represents a very important biological risk factors and that size, actually, has a serious consideration in malignancy assessment.

Diagnostic Imaging is a highest tool for early diagnosis in order to change the course of the disease. We point out the important acquisition of a well structured informed consent prior to surgery, which prospects a small chance that before thorough sectioning of the surgical specimen, such small lesions could be missed or be technically not feasible by pathology techniques.

\section{ACKNOWLEDGMENTS}

The authors thank for their support: Foundation T \& L de Beaumont Bonelli for Cancer Research Naples - Italy. University Hospital of Campania L.Vanvitelli - Medical School Naples - Italy \& San Matteo Diagnostic Research - Italy.

\section{CONFLICTS OF INTEREST}

The authors declare no conflict of interests.

\section{REFERENCES}

1. Hedinger C, Williams ED, Sobin LH. The WHO histological classification of thyroid tumors: a commentary on the second edition. Cancer. 1989; 63:908-11.

2. Lastra RR, LiVolsi VA, Baloch ZW. Aggressive variants of follicular cell-derived thyroid carcinomas: a cytopathologist's perspective. Cancer Cytopathol. 2014; 122:484-503. https://doi.org/10.1002/cncy.21417.

3. Gikas PW, Labow SS, DiGiulio W, Finger JE. Occult metastasis from occult papillary carcinoma of the thyroid. Cancer. 1967; 20:2100-04. https://doi. org/10.1002/1097-0142(196712)20:12\%3C2100::AIDCNCR2820201207\%3E3.0.CO;2-O.

4. Silver CE, Owen RP, Rodrigo JP, Rinaldo A, Devaney $\mathrm{KO}$, Ferlito A. Aggressive variants of papillary thyroid carcinoma. Head Neck. 2011; 33:1052-59. https://doi.org/10.1002/hed.21494.

5. Trapanese E, Agrusta M, D’Arco E, Tarro G. Insidious rare thyroid microcarcinoma "Black Ink". Indian J Appl Res. 2017; 7:67.
6. Jemal A, Siegel R, Ward E, Hao Y, Xu J, Murray T, Thun MJ. Cancer statistics, 2008. CA Cancer J Clin. 2008; 58:7196. https://doi.org/10.3322/CA.2007.0010.

7. Fukunaga FH, Yatani R. Geographic pathology of occult thyroid carcinomas. Cancer. 1975; 36:1095-99. https://doi. org/10.1002/1097-0142(197509)36:3\%3C1095::AID-CNC R2820360338\%3E3.0.CO;2-9.

8. Tarro GF, Tarro G. Cancer should be only a zodiac sign. Naples. 2015.

9. Sampson RJ, Key CR, Buncher CR, Iijima S. Thyroid carcinoma in Hiroshima and Nagasaki. I. Prevalence of thyroid carcinoma at autopsy. JAMA. 1969; 209:65-70. https://doi.org/10.1001/jama.1969.03160140021004.

10. Li QS, Chen SH, Xiong HH, Xu XH, Li ZZ, Guo GQ. Papillary thyroid carcinoma on sonography. Clin Imaging. 2010; 34:121-26. https://doi.org/10.1016/j.clinimag.2009.03.003.

11. Kim GR, Kim MH, Moon HJ, Chung WY, Kwak JY, Kim EK. Sonographic characteristics suggesting papillary thyroid carcinoma according to nodule size. Ann Surg Oncol. 2013; 20:906-13. https://doi.org/10.1245/s10434-012-2830-4.

12. Amoako-Tuffour Y, Graham ME, Bullock M, Rigby MH, Trites J, Taylor SM, Hart RD. Papillary thyroid cancer recurrence 43 Years following Total Thyroidectomy and radioactive iodine ablation: a case report. Thyroid Res. 2017; 10:8. https://doi.org/10.1186/s13044-017-0043-4.

13. Durna YM, Yigit O, Acioglu E, Gunver F. The case of papillary thyroid carcinoma presented with lumbar spine metastasis. Otolaryngology. 2015; 5:189. https://doi.org/10.4172/2161-119X.1000189.

14. Heling KS, Chaoui R, Bollmann R. Advanced dynamic flow - a new method of vascular imaging in prenatal medicine. A pilot study of its applicability. Ultraschall Med. 2004; 25:280-84. https://doi.org/10.1055/s-2004-813383.

15. Berker D, Aydin Y, Ustun I, Gul K, Tutuncu Y, Işik S, Delibasi T, Guler S. The value of fine-needle aspiration biopsy in subcentimeter thyroid nodules. Thyroid. 2008; 18:603-08. https://doi.org/10.1089/thy.2007.0313.

16. Zhao Q, Ming J, Liu C, Shi L, Xu X, Nie X, Huang T. Multifocality and total tumor diameter predict central neck lymph node metastases in papillary thyroid microcarcinoma. Ann Surg Oncol. 2013; 20:746-52. https://doi.org/10.1245/s10434-012-2654-2.

17. Ghossein R, Ganly I, Biagini A, Robenshtok E, Rivera M, Tuttle RM. Prognostic factors in papillary microcarcinoma with emphasis on histologic subtyping: a clinicopathologic study of 148 cases. Thyroid. 2014; 24:245-53. https://doi.org/10.1089/thy.2012.0645.

18. Kasai N, Sakamoto A. New subgrouping of small thyroid carcinomas. Cancer. 1987; 60:1767-70. https://doi. org/10.1002/1097-0142(19871015)60:8\%3C1767::AIDCNCR2820600816\%3E3.0.CO;2-P.

19. Gu WJ, Yan HX, Luo YK, Wang FL, Yang GG, Guo QH, Jin N, Zang L, Chen K, Du J, Wang XL, Yang LJ, Ba JM, et al. 
Characterization of Papillary thyroid microcarcinomas using sonographic features in malignant papillary thyroid cancer: a retrospective analysis. Tian. C, ed. Medicine. 2015; 94:841. https://doi.org/10.1097/MD.0000000000000841.

20. Nardi F, Basolo F, Crescenzi A, Fadda G, Frasoldati A, Orlandi F, Palombini L, Papini E, Zini M, Pontecorvi A, Vitti P. Italian consensus for the classification and reporting of thyroid cytology. J Endocrinol Invest. 2014; 37:593-99. https://doi.org/10.1007/s40618-014-0062-0.

21. Cibas ES, Ali SZ. The bethesda system for reporting thyroid cytopathology. Thyroid. 2009; 19:1159-65. https://doi.org/10.1089/thy.2009.0274.

22. Yu XM, Wan Y, Sippel RS, Chen H. Should all papillary thyroid microcarcinomas be aggressively treated? An analysis of 18,445 cases. Ann Surg. 2011; 254:653-60. https://doi.org/10.1097/SLA.0b013e318230036d.

23. Jonklaas J, Nogueras-Gonzalez G, Munsell M, Litofsky D, Ain KB, Bigos ST, Brierley JD, Cooper DS, Haugen BR, Ladenson PW, Magner J, Robbins J, Ross DS, et al, and National Thyroid Cancer Treatment Cooperative Study Group. The impact of age and gender on papillary thyroid cancer survival. J Clin Endocrinol Metab. 2012; 97:E87887. https://doi.org/10.1210/jc.2011-2864.

24. Ito Y, Kudo T, Kobayashi K, Miya A, Ichihara K, Miyauchi A. Prognostic factors for recurrence of papillary thyroid carcinoma in the lymph nodes, lung, and bone: analysis of 5,768 patients with average 10-year follow-up. World J Surg. 2012; 36:1274 78. https://doi.org/10.1007/s00268-012-1423-5.

25. Cao J, Chen C, Chen C, Wang QL, Ge MH. Clinicopathological features and prognosis of familial papillary thyroid microcarcinoma - a large - scale, matched, case-control study. Clinical Endocrinology. 2015; 84:598-606. https://doi.org/10.1111/cen.12859.

26. Hay ID, Grant CS, Taylor WF, McConahey WM. Ipsilateral lobectomy versus bilateral lobar resection in papillary thyroid carcinoma: a retrospective analysis of surgical outcome using a novel prognostic scoring system. Surgery. 1987; 102:1088-95.

27. Lee J, Rhee Y, Lee S, Ahn CW, Cha BS, Kim KR, Lee HC, Kim SI, Park CS, Lim SK. Frequent, aggressive behaviors of thyroid microcarcinomas in korean patients. Endocr J. 2006; 53:627-32. https://doi.org/10.1507/endocrj.K06-013.

28. Page C, Biet A, Boute P, Cuvelier P, Strunski V. 'Aggressive papillary' thyroid microcarcinoma. Eur Arch Otorhinolaryngol. 2009; 266:1959-63. https://doi.org/10.1007/s00405-009-0952-5.

29. Campana FP, Marchesi M, Biffoni M, Tartaglia F, Nuccio G, Stocco F, Jaus MO, Nobili Benedetti R, Faloci C, Mastropietro T, Millarelli M. [Total thyroidectomy technique: suggestions and proposals of surgical practice]. [Article in Italian]. Ann Ital Chir. 1996; 67:627-35.

30. Hwangbo Y, Kim JM, Park YJ, Lee EK, Lee YJ, Park DJ, Choi YS, Lee KD, Sohn SY, Kim SW, Chung JH, Lim DJ, Kim MH, et al. Long-term recurrence of small papillary thyroid cancer and its risk in a korean multicenter study. J Clin Endocrinol Metab. 2017; 102:625-33. https://doi.org/10.1210/jc.2016-2287.

31. Yokozawa T, Miyauchi A, Kuma K, Sugawara M. Accurate and simple method of diagnosing thyroid nodules the modified technique of ultrasound-guided fine needle aspiration biopsy. Thyroid. 1995; 5:141-45. https://doi.org/10.1089/thy.1995.5.141.

32. Ahuja S, Ernst H, Lenz K. Papillary thyroid carcinoma: occurrence and types of lymph node metastases. J Endocrinol Invest. 1991; 14:543-49. https://doi.org/10.1007/BF03346863.

33. Amin MB, Edge SB, Greene FI, et al. American Joint Committee an Cancer (AJCC). Cancer Staging Manual. 8th ed. New York: Springer; 2017.

34. World Health Organization. Histological typing of thyroid tumor. International histological classification of tumor. N Geneva. 1974; 11:21-24.

35. Rosai J, Carangiu ML, Lellis RA. Tumors of the thyroid gland. Atlas of tumor pathology. Armed Forces Institute of Pathology. Washington; 1990.

36. Kuo EJ, Goffredo P, Sosa JA, Roman SA. Aggressive variants of papillary thyroid microcarcinoma are associated with extrathyroidal spread and lymph-node metastases: a population-level analysis. Thyroid. 2013; 23:1305-11. https://doi.org/10.1089/thy.2012.0563.

37. Hefer T, Joachims HZ, Hashmonai M, Ben-Arieh Y, Brown J. Highly aggressive behaviour of occult papillary thyroid carcinoma. J Laryngol Otol. 1995; 109:1109-12. https://doi.org/10.1017/S0022215100132165.

38. Ardito G, Revelli L, Giustozzi E, Salvatori M, Fadda G, Ardito F, Avenia N, Ferretti A, Rampin L, Chondrogiannis S, Colletti PM, Rubello D. Aggressive papillary thyroid microcarcinoma: prognostic factors and therapeutic strategy. Clin Nucl Med. 2013; 38:25-28. https://doi.org/10.1097/RLU.0b013e318279bc65.

39. Yamamoto Y, Maeda T, Izumi K, Otsuka H. Occult papillary carcinoma of the thyroid. A study of 408 autopsy cases. Cancer. 1990; 65:1173-79. https://doi. org/10.1002/1097-0142(19900301)65:5\%3C1173::AIDCNCR2820650524\%3E3.0.CO;2-2.

40. Roti E, Rossi R, Trasforini G, Bertelli F, Ambrosio MR, Busutti L, Pearce EN, Braverman LE, Degli Uberti EC. Clinical and histological characteristics of papillary thyroid microcarcinoma: results of a retrospective study in 243 patients. J Clin Endocrinol Metab. 2006; 91:2171-78. https://doi.org/10.1210/jc.2005-2372.

41. Hawk WA, Hazard JB. The many appearances of papillary carcinoma of the thyroid. Cleve Clin Q. 1976; 43:207-15.

42. Lim YC, Choi EC, Yoon YH, Kim EH, Koo BS. Central lymph node metastases in unilateral papillary thyroid microcarcinoma. Br J Surg. 2009; 96:253-57. https://doi.org/10.1002/bjs.6484.

43. Zhang L, Wei WJ, Ji QH, Zhu YX, Wang ZY, Wang Y, Huang CP, Shen Q, Li DS, Wu Y. Risk factors for neck 
nodal metastasis in papillary thyroid microcarcinoma: a study of 1066 patients. J Clin Endocrinol Metab. 2012; 97:1250-57. https://doi.org/10.1210/jc.2011-1546.

44. Chang YW, Kim HS, Kim HY, Lee JB, Bae JW, Son GS. Should central lymph node dissection be considered for all papillary thyroid microcarcinoma? Asian J Surg. 2016; 39:197-201.
45. Wang $\mathrm{M}, \mathrm{Wu}$ WD, Chen GM, Chou SL, Dai XM, Xu JM, Peng ZH. Could tumor size be a predictor for papillary thyroid microcarcinoma: a retrospective cohort study. Asian Pac J Cancer Prev. 2015; 16:8625-28. https://doi.org/10.7314/APJCP.2015.16.18.8625. 